\title{
PERBANDINGAN ANTARA KETEGUHAN REKAT LEM PUTIH DENGAN LEM KUNING PADA KARPET KAYU
}

\section{Comparison between Shear Strength of White and Yellow Glue on Wooden Carpets}

\section{Sigit Baktya Prabawa}

Balai Penelitian dan Pengembangan Kehutanan Lingkungan Hidup dan Kehutanan Kupang

Jl. Alfons Nisnoni No. 7 (Belakang), Airnona - Kupang - NTT 85115

Email: zsbprabawa@gmail.com

\section{Diterima 8 September 2020/Disetujui 1 Oktober 2020}

\begin{abstract}
Wooden carpets are one of the products made of woody materials glued on the textiles. The wooden part can be in the form of plywood or solid wood, while the textiles as a carpet backing serves as a link between the pieces of woody material that make up the carpet. Compared to fabric carpets, wood carpets have several advantages in terms of health and maintenance. Wood carpet generally include woody material, fabrics, glue and finishing materials. The glue serves as an adhesive between woody material and fabric. The shear strength of glue adhesives has an important role in wood carpet products. In the local market there are several types of glue such as white glue (Polyvinyl Acetate) and yellow glue (Synthetic Rubber). The purpose of this study was to compare the shear strength of white and yellow glue. It is expected that people can choose the type of glue that is more suitable for wood carpets. The research data was tabulated and analysed by paired t-test. The results showed that the shear strength of white and yellow glue using manual clamps were $27.95 \mathrm{~kg} \mathrm{~cm}^{-2}$ and $13.78 \mathrm{~kg} \mathrm{~cm}^{-2}$ respectively. The shear strength of white glue strongly differ with those of yellow glue, and greather two times than the yellow one. In making or producing wooden carpets, it is recommanded to use white glue instead of yellow one and can apply manual clamps. However, for better results, it is recommended to apply a press machine.
\end{abstract}

Keywords:PVAc, Shear Strength, White Glue, Wood Carpets, Yellow Glue 


\section{PENDAHULUAN}

Karpet merupakan kain berbahan tebal dengan berbagai dekoratif yang dikelompokkan sebagai penutup lantai (Britanica Encyclopedia, 2020). Karpet juga dapat diartikan sebagai lembaran atau lapisan yang menyerupai atau diperuntukan karpet (Merriam-Webster Dictionary, 2020). Secara lebih khusus Prabawa (2018) menyebutkan bahwa karpet kayu merupakan salah satu produk hasil hutan berupa karpet atau sejenis karpet yang terbuat dari bahan berkayu yang direkatkan pada kain. Kain dalam hal ini berfungsi sebagai penghubung antara potongan-potongan bahan berkayu penyusun karpet yang satu dengan yang lainnya.

Karpet juga dapat diartikan sebagai suatu produk berbentuk lembaran yang biasanya diletakkan di atas lantai atau berfungsi sebagai penutup lantai (MerriamWebster Dictionary, 2020). Pada umumnya karpet memiliki sifat dapat digulung serta mudah dipindahkan, demikian juga halnya dengan karpet kayu (Prabawa, 2018). Karpet kayu dalam hal ini termasuk kategori mebel atau furnitur karena mebel merupakan suatu perkakas yang diperlukan, bermanfaat atau dikehendaki sebagai barang-barang yang dapat atau mudah dipindahkan untuk digunakan atau ditempatkan dalam suatu ruangan atau beranda (Merriam-Webster Dictionary, 2020). Dalam hal ini pulalah maka karpet kayu berbeda dengan produk lantai kayu, karena lantai kayu tetap pada tempatnya dan dirancang untuk tidak dipindah-pindahkan.

Menurut Prabawa (2018), bila dibandingkan dengan jenis karpet kain (karpet konvensional) karpet kayu memiliki beberapa keunggulan khususnya dalam hal kesehatan dan pemeliharaannya dibanding karpet yang terbuat dari kain. Menurut Merle (2017) karpet konvensional dapat mengandung alergen sekitar 100 kali lebih banyak daripada karpet kayu keras. Karpet konvensional juga dapat menangkap atau menyimpan debu yang lebih besar dari karpet kayu. Satu meter persegi karpet dapat menampung sekitar 67 gram debu. Tungau debu dapat menghasilkan hingga 200 kali lipat bobot tubuh mereka setiap hari. Manusia tidak alergi terhadap tungau debu, tetapi terhadap limbah tungau debu. Hal ini berarti bahwa untuk setiap 1 tungau debu yang menghuni karpet konvensional, 200 kali alergen beratnya dilepaskan ke kamar atau rumah mereka setiap hari (Merle, 2017). Keunggulan lainnya perawatan atau pembersihan karpet kayu ini juga lebih mudah dan lebih murah daripada yang konvensional (Prabawa, 2018). Karena itu, bukan tidak mungkin jika di masa depan produk karpet jenis kayu ini memiliki peluang besar dapat menggantikan posisi produk karpet konvensional.

Masyarakat umumnya belum banyak mengenal jenis karpet ini karena jenis karpet ini sampai saat ini belum umum dijual secara komersial baik di toko-toko 
penjual karpet maupun di toko-toko penjual mebel. Prabawa (2018) menyebutkan bahwa komponen karpet kayu ini umunya terdiri dari empat unsur bahan yakni berupa bahan berkayu, kain, lem dan bahan finishing. Bahan berkayu dapat berupa kayu utuh atau plywood. Bahan berkayu ini berfungsi sebagai bagian permukaan karpet. Bahan kain sebagai bagian bawah dari karpet berfungsi sebagai penghubung antara potongan-potongan bahan berkayu tersebut. Lem sebagai bahan perekat atau pengikat antara bahan berkayu dengan kain. Sedangkan bahan finishing sebagai bahan untuk menjadikan penampilan karpet kayu lebih menarik.

Bahan berkayu yang dipakai membuat karpet berupa kayu utuh, maka kayu utuh disini dapat berupa potongan-potongan kayu atau berbentuk kayu strip yang mana dimensinya umumnya berukuran kecil-kecil. Karena dimensi bahan berkayu yang kecil-kecil ini, maka bahan berkayu dari karpet kayu ini dapat memanfaatkan limbah. Pembuatan karpet kayu dengan memanfaatkan limbah selain mendukukung komitmen terhadap pemanfaatan hasil hutan secara lestari juga akan memperpanjang usia penyimpanan karbon. Hal ini berarti bahwa aktivitas pembuatan kartpet kayu dari limbah juga turut mendukung komitmen Indonesia dalam mengurangi emisi Gas Rumah Kaca (GRK) seperti yang tersirat dalam buku Strategi Implementasi NDC (Masripatin et.al., 2017).

Produk karpet kayu juga sangat bergantung kepada keteguhan rekat lem agar dapat berfungsi dengan baik. Di pasar lokal khususnya di toko-toko bahan bangunan dijual berbagai jenis lem. Beberapa jenis lem yang umum dijumpai untuk mengelem bahan berkayu tersebut antara lain lem putih (Polyvinyl Acetat PVAc) dan jenis lem kuning (Syntethic Rubber), namun diantara keduanya belum diketahui jenis lem yang memiliki daya rekat yang baik bagi pembuatan karpet kayu. Oleh karena itu tujuan dari penelitian ini adalah untuk mebandingkan keteguhan rekat antara lem putih dengan lem kuning yang ada di pasar lokal pada karpet kayu. Hasil penelitian ini diharapkan masyarakat yang ingin membuat atau memproduksi karpet kayu dapat memilih jenis lem yang lebih sesuai untuk karpet kayu.

\section{METODE PENELITIAN}

\section{Penyiapan Contoh Uji}

Penyiapan contoh uji telah dilaksanakan di Laboratorium Hasil Hutan Balai Penelitian dan Pengembangan Kehutanan Kalimantan (Sekarang Balai Besar Penelitian dan Pengembangan Ekosistem Hutan Dipterokarpa) di Samarinda, Kalimantan Timur. Untuk pengujian keteguhan rekat antara kayu dengan kain telah dilakukan dengan alat UTM (Universal Testing Machine) di Laboratorium 
Hasil Hutan Fakultas Kehutanan Universitas Mulawarman di Samarinda, Kalimantan Timur.

Bahan utama dalam penelitian ini meliputi kayu utuh, kain dan lem kayu. Kayu dari jenis kayu Bangkirai (Shorea laevis Ridl.) (Martawijaya, 2005) yang diperoleh dari penjual kayu lokal di Samarinda. Kain diperoleh di toko textil di Samarinda. Kain terdiri dari 6 jenis kain yang dipilih secara acak dan dipakai sebagai ulangan, sehingga dalam penelitian ini melibatkan 6 ulangan. Lem yang digunakan dalam penelitian ini adalah lem putih (Polyvinyl Acetate - PVAc) dan lem kuning (Syntethic Rubber) yang diperoleh dari toko bahan bangunan di Samarinda. Adapun peralatan yang dipakai antara lain meliputi gergaji, alat serut kayu, gunting, pisau cutter, caliper, penggaris,kertas transparan bergaris, alat klem manual dan Universal Testing Machine (UTM).

\section{Pengujian Keteguhan Rekat Lem}

Kekuatan rekat resin antara kayu dan kain dilakukan dengan dengan cara merekatkan kain antara 2 lembar contoh uji kayu dengan ukuran masing-masing kayu sekitar 2,5 x 5 × 6 cm. Untuk ulangan dilakukan sebanyak 6 kali ulangan. Contoh uji untuk keteguhan rekat disajikan pada Gambar 1. Area untuk uji keteguhan rekat antara kayu dengan kain ditunjukan oleh area yang berwarna hitam, sedangkan panah hitam menunjukan arah gaya (Gambar 1).

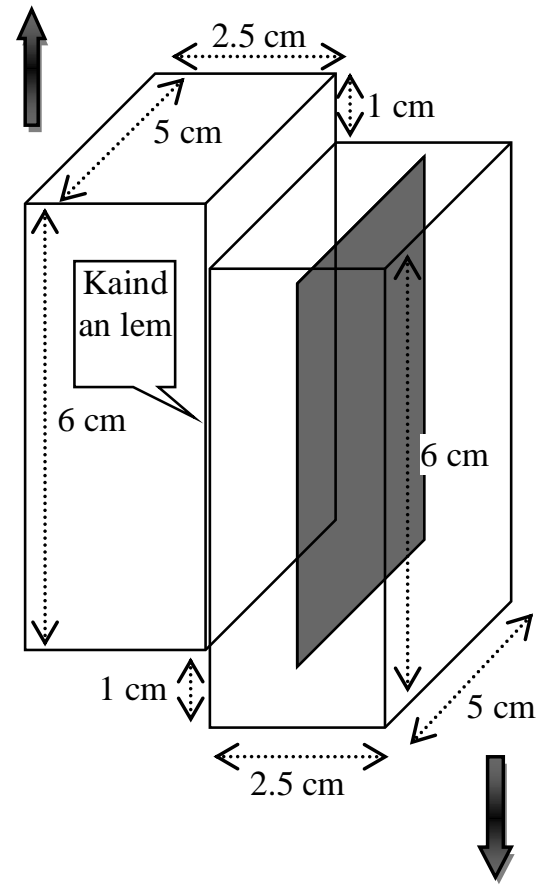

Gambar 1. Ukuran contoh uji keteguhan rekat 
Mula-mula kedua permukaan dari kedua contoh uji dilaburi dengan lem dengan luas permukaan yang dilem masing-masing sekitar $5 \mathrm{~cm}$ x $5 \mathrm{~cm}$. Kemudian contoh uji kain diletakan di antara kedua permukaan kayu tersebut. Setelah dilem setiap contoh uji diklem dengan klem manual selama 24 jam pada suhu kamar. Contoh uji dari masing-masing jenis lem dijepit atau diklem secara bersama-sama pada satu alat klem agar dapat dibandingkan. Contoh uji yang telah diklem tersebut lalu dilakukan pengerasan (curring) atau diangin-anginkan selama satu minggu. Setelah itu terhadap contoh uji tersebut dilakukan pengujian keteguhan rekatnya dengan menggunakan alat UTM. Untuk lebih jelasnya proses atau tahapan mulai dari penyiapan contoh uji hingga pengujian contoh uji maka disajikan diagram alur seperti yang ditampilkan pada Gambar 2.

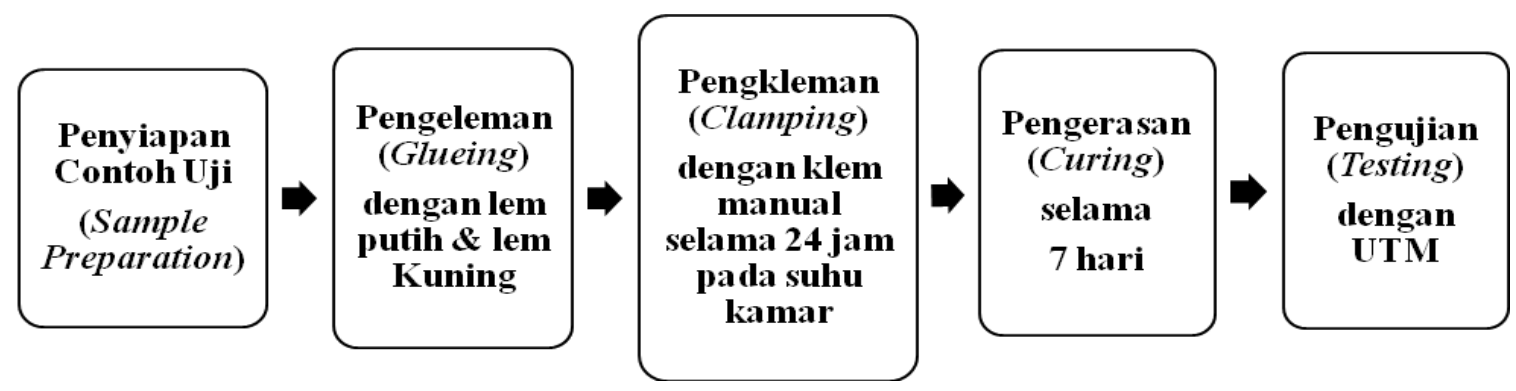

Gambar 2. Diagram alur prosedur pengujian keteguhan rekat karpet kayu

Keteguhan rekat merupakan beban maksimum dari suatu komopenen yang dapat dipertahankan sebelum mengalami kerusakan akibat adanya beban tersebut dibagi dengan luas bidang rekat yang diuji (Azom 2018). Keteguhan rekat dihitung dengan membagi beban maksimum dengan luas bidang uji dengan rumus sebagai berikut:

$$
K R=\frac{F(\operatorname{Max})}{A d}
$$

Dimana:

$\mathrm{KR}=$ Keteguhan Rekat $\left(\mathrm{kg} \mathrm{cm}^{-2}\right)$

$\mathrm{F}(\mathrm{Max})=$ Beban Maximum $(\mathrm{kg})$

Ad $\quad=$ Luas Bidang Uji yang rusak setelah dilakukan pengujian $\left(\mathrm{cm}^{2}\right)$

Luas bidang uji yang mengalami kerusakan setelah dilakukan pengujian diukur dengan menggunakan kertas transparan bergaris/berukuran. Ukuran contoh uji untuk sifat keteguhan rekat ini dapat dilihat pada Gambar 1. Data primer yang diperoleh dari hasil uji keteguhan rekat kemudian ditabulasi dan 
dianalisa serta dibandingkan dengan menggunakan perangkat uji-t berpasangan (paired t-test) dan data diolah dengan menggunakan aplikasi software Minitab.

\section{HASIL DAN PEMBAHASAN}

Hasil dari pengujian mengenai pengaruh jenis lem terhadap sifat keteguhan rekat karpet kayu telah dilakukan pengukuran keteguhan rekatnya. Pengujian keteguhan rekat telah dilakukan pada dua macam lem yakni lem putih dan lem kuning masing-masing sebanyak enam (6) ulangan. Selain itu sebagai bahan pembanding pengujian keteguhan rekat tanpa kain juga telah diamati. Data primer berupa beban geser dan keteguhan rekat tersebu tkemudian ditabulasi dan ditampilkan dalam Tabel 1. Untuk mempermudah perbandingan keteguhan rekat antara kedua jenis lem secara visual, maka secara grafis data keteguhan rekat dari kedua jenis lem tersebut disajikan pada Gambar 3.

Tabel 1 Beban geser maksimum dan keteguhan rekat karpet kayu yang diuji

\begin{tabular}{lcccc}
\hline & \multicolumn{4}{c}{ Jenis Lem } \\
\cline { 2 - 5 } Ulangan (Jenis Kain) & $\begin{array}{c}\text { Lem Putih } \\
\text { Maksimum (Kg) }\end{array}$ & $\begin{array}{c}\text { Keteguhan Rekat } \\
\left(\mathrm{Kg} \mathrm{Cm}^{-2}\right)\end{array}$ & $\begin{array}{c}\text { Beban Geser } \\
\text { Maksimum }(\mathrm{Kg})\end{array}$ & $\begin{array}{c}\text { Keteguhan Rekat } \\
\left(\mathrm{Kg} \mathrm{Cm}^{-2}\right)\end{array}$ \\
\hline Jean (Ulangan1) & 957 & 9,32 & 426 & 18,16 \\
Twil Tebal (Ulangan 2) & 660 & 27,06 & 243 & 10,00 \\
Twil Tipis (Ulangan 3) & 406 & 23,18 & 190 & 15,01 \\
Belacu Tebal (Ulangan 4) & 612 & 24,76 & 154 & 12,22 \\
Belacu Tipis (Ulangan 5) & 777 & 33,18 & 121 & 15,04 \\
Wuring (Ulangan 6) & 475 & 20,18 & 182 & 12,22 \\
Rerata & & 27,95 & & 13,78 \\
Simpangan Baku & & 7,08 & & 2,88 \\
Tanpa kain (kayu dengan & 1015 & 45,27 & 425 & 19,29 \\
kayu) & & & & \\
\hline
\end{tabular}

Tabel 1 terlihat bahwa nilai rerata keteguhan rekat menggunakan lem putih mencapai $27,95 \mathrm{~kg} \mathrm{~cm}$-2 sedangkan yang menggunakan lem kuning hanya mencapai sekitar $13,78 \mathrm{~kg} \mathrm{~cm}^{-2}$. Apabila nilai ini diperhatikan dalam Gambar 3 terlihat bahwa tinggi diagram batang yang berwarna hitam (mewakili keteguhan rekat lem kuning) kira-kira hanya sekitar separuh dari tinggi diagram batang yang berwarna putih (mewakili keteguhan rekat lem putih), dan hal ini terjadi baik 
dengan atau tanpa kain (Gambar 3). Dengan kata lain dapat dikatakan bahwa keteguhan rekat lem putih lebih besar sekitar dua kali lipat dari pada keteguhan rekat lem kuning.

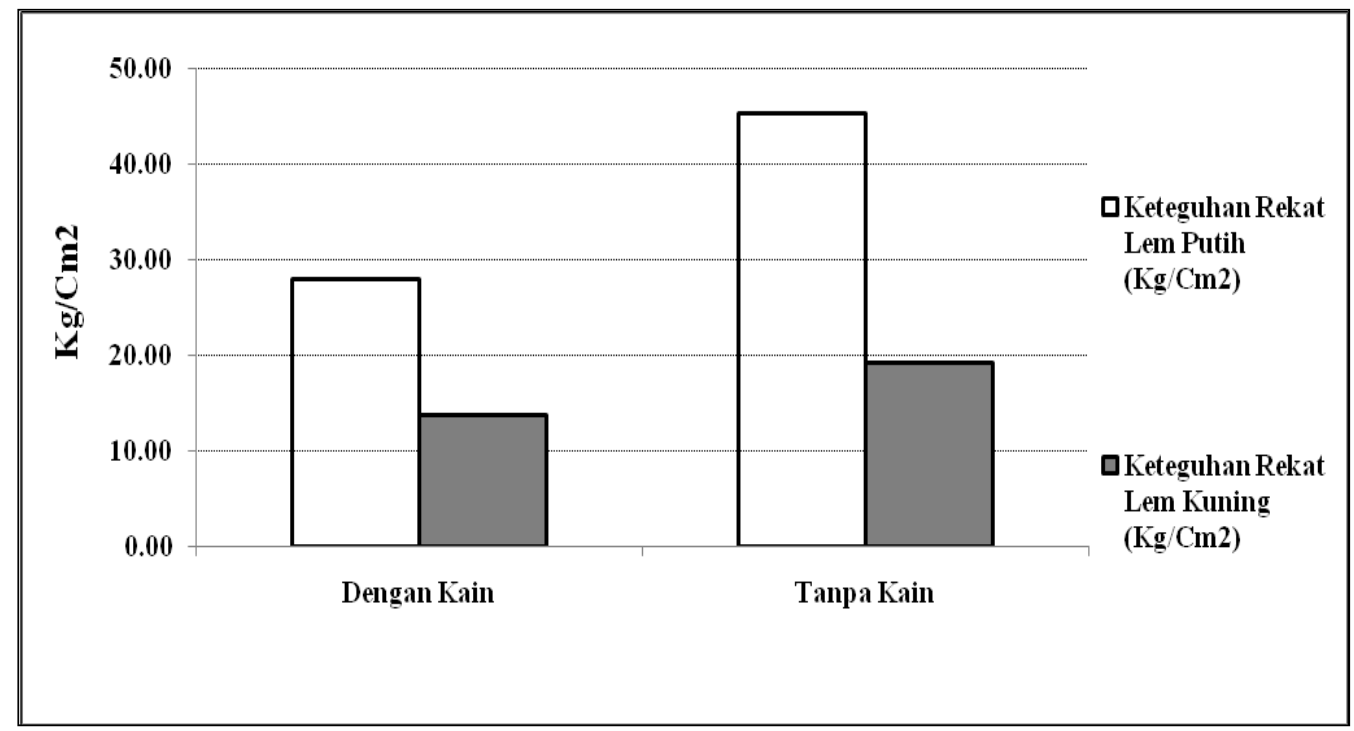

Gambar 3. Diagram batang keteguhan rekat lem putih dan lem kuning pada karpet kayu

Berdasarkan hasil analisis uji-t berpasangan dinyatakan bahwa terjadi perbedaan nilai yang sangat signifikan antara keteguhan rekat lem putih dan lem kuning. Hasil uji-t ini memvalidasi bahwa nilai keteguhan rekat lem putih memang betul-betul lebih besar dari keteguhan rekat yang menggunakan lem kuning. Bukti ini sekaligus memperkuat bahwa keteguhan rekat lem putih lebih besar sekitar dua kali lipat dari keteguhan rekat yang menggunakan lem kuning.

Hal ini berimplikasi bahwa dalam membuat atau memproduksi karpet kayu yang lebih baik, masyarakat dapat memilih jenis lem putih dari pada lem kuning. Selain itu jenis lem puti (PVAC) ini memiliki sifat yang tidak beracun sehingga aman bila digunakan sebagai lem untuk barang-barang perabotan atau perlengkapan rumah tangga yang biasanya ditempatkan di dalam rumah seperti karpet kayu ini. Bahkan perekat PVAC ini setelah mengering menghasilkan film bening (garis rekat transfaran) dan keras yang memiliki ketahanan cuaca yang baik dan tahan air, gemuk, minyak, dan minyak bumi serta memiliki ketahanan yang baik terhadap biodegradasi (Kaboorani \& Riedl 2015) sehingga sangat cocok bila diaplikasikan untuk karpet kayu.

Menurut Ebnesajjad (2011) kekuatan ikatan maksimum lem putih (PVAc) dapat mencapai sekitar $14 \mathrm{MPa}$ (Mega Pascal) atau sekitar 151,16 kg cm${ }^{-2}$. Selain itu, untuk keperluan ikatan kayu direkomendasikan menggunakan tekanan 10,20 
$\mathrm{kg} \mathrm{cm}{ }^{-2}$ pada $20{ }^{\circ} \mathrm{C}$ selama 10 menit hingga 3 jam (Ebnesajjad 2011). Padahal berdasarkan Tabel 1 kekuatan rekat lem putih paling tinggi mencapai sekiktar $39,32 \mathrm{~kg} \mathrm{~cm}^{-2}$ (dengan kain) dan mencapai sekitar 45,27 (tanpa kain) yang hanya sekitar sepertiga dari kekuatan ikatan maksimum PVAc. Ini kemungkinan besar karena kekuatan tekanan klem manual kurang dari atau jauh di bawah 10,20 kg $\mathrm{cm}^{-2}$. Hal ini karena dalam penelitian ini untuk mengikat kayu dan kain dengan lem dilakukan dengan menggunakan penjepit/klem manual yang diaplikasikan menggunakan tenaga manusia dalam memutar sekrup di mana kekuatan tekanan klem jauh di bawah kekuatan pengepresan jika diterapkan menggunakan mesin pres.

Informasi di atas memberikan gambaran bahwa keteguhan rekat lem putih untuk produksi karpet kayu memang masih dapat ditingkatkan dengan cara menggunakan mesin pres dari pada menggunakan klem manual. Namun demikian peneitian dengan menggunakan klem manual ini penting untuk dilakukan dengan pertimbangan bahwa klem manual lebih murah sehingga masyarakat kalangan bawah diharapkan dapat lebih mudah dalam membuat karpet kayu.

Harsono (2012) melaporkan bahwa telah melakukan penelitian penggunaan perekat PVAC pada glulam kayu karet dan batang kelapa dengan menggunakan klem manual pada suhu kamar selama 24 jam. Hasil penelitiannya memperlihatkan bahwa keteguhan rekat dari perekat tersebut berkisar sekitar 23 $\mathrm{kg} \mathrm{cm} \mathrm{cm}^{-2}$ hingga sekitar $45 \mathrm{~kg} \mathrm{~cm}^{-2}$. Kisaran hasil penelitian Harsono ini mirip dengan hasil dari kegiatan penelitian ini. Hal ini mengindikasikan bahwa keteguhan rekat dari perekat PVAC menggunakan klem manual pada suhu kamar selama 24 jam baik yang diaplikasikan pada karpet kayu maupun yang diaplikasikan pada glulam dari kayu karet dan batang kelapa memperlihatkan hasil yang tidak jauh berbeda. Berdasarkan hal ini dapat dilakukan pendekatan bahwa keteguhan rekat lem PVAC yang diaplikasikan menggunakan klem manual pada suhu kamar selama 24 jam diprediksi menghasilkan keteguhan rekat yang hanya berkisar sekitar $20 \mathrm{~kg} \mathrm{~cm}^{-2}$ hingga $50 \mathrm{~kg} \mathrm{~cm}^{-2}$.

Sementara itu Standar Industri Indonesia (SNI) Nomor 06-6049-1999 mempersyaratkan bahwa kekuatan atau daya rekat dari perekat PVAC untuk pengerjaan kayu setidaknya harus $100 \mathrm{~kg} \mathrm{~cm}^{-2}$ (BSN, 1999). Hal ini berarti bahwa kekuatan rekat dari perekat PVAC yang diaplikasikan menggunakan alat pres manual diperkirakan hanya mencapai $20 \%$ hingga 50\% dari minimal kekuatan rekat yang dipersyaratkan oleh SNI 06-6049-1999. Kekuatan rekat sebesar ini kemungkinan besar tidak akan dapat dicapai apabila pada proses perekatannya hanya menggunakan atau melibatkan alat press atau alat klem manual dan bukan alat pres mesin. 
Hasil ini berarti bahwa kekuatan rekat dari perekat PVAC yang diaplikasikan menggunakan alat pres manual diperkirakan hanya mencapai $20 \%$ hingga 50\% dari minimal kekuatan rekat yang dipersyaratkan oleh SNI 06-60491999. Karena itu diperlukan revisi standar SNI atau usulan standar SNI yang baru khususnya untuk karpet kayu dengan cara menurunkan nilai yang dipersyaratkan, agar hasil keteguhan rekatnya memenuhi standar dan agar masyarakat dapat membuat atau memproduksi serta menjual karpet kayu yang memenuhi standar.

Meskipun keteguhan rekat lem PVAC yang dipres dengan alat manual hasilnya berkisar sekitar $20 \mathrm{~kg} \mathrm{~cm}^{-2}$ hingga $50 \mathrm{~kg} \mathrm{~cm}^{-2}$, namun keteguhan rekat ini untuk karpet kayu cukup memadai karena tidak ada pembebanan secara struktural. Pembebanan yang terjadi adalah dari beban bobotnya karpet kayu itu sendiri ketika digulung atau ketika karpet kayu itu diangkat untuk digulung atau dipindahkan. Sementara proses pembebanannyapun tidak terlalu lama.

Selain itu pada penelitian tersebut, beban geser maksimum yang dihasilkan dengan keteguhan rekat lem PVAC tersebut berkisar sekitar $400 \mathrm{~kg}$ hingga sekitar $1000 \mathrm{~kg}$ (Tabel 1). Sementara itu bobot dalam satu lembar karpet kayu (tergantung ukuran) umumnya tidak sampai mencapai $100 \mathrm{~kg}$ per lembar. Jadi walaupun nilai persyaratan Standar SNI tersebut diusulkan untuk diturunkan, namun dalam aplikasinya konsumen sebagai pembeli atau pengguna karpet kayu tidak akan merugi karena lem tidak akan rusak hanya oleh karena karpet kayu dipindah digulung atau diangkat.

\section{KESIMPULAN}

Keguhan rekat lem putih sekitar $27,95 \mathrm{~kg} \mathrm{~cm}^{-2}$ dan keteguhan rekat lem kuning sekitar $13,78 \mathrm{~kg} \mathrm{~cm}^{-2}$. Keteguhan rekat lem putih berbeda sangat nyata dengan keteguhan lem kuning, dimana keteguhan rekat lem putih lebih besar sekitar dua kali lipat dari keteguhan rekat lem kuning. Keteguhan rekat lem putih masih dapat ditingkatkan dengan cara memperbesar tekanannya pada saat dilakukan pengepresan dengan menggunakan mesin pres.

\section{DAFTAR PUSTAKA}

Azom. (2018). Defining the Tensile, Compressive, Shear, Torsional and Yield Strength of Materials. Retrieved from 28 Agustus 2020 from Article $e I D=3426$. https://www.azom.com/article.aspx?ArticleID=3426

BSN. (1999). Standar Nasional Indonesia (06-6049-1999): Polivinil Asetat Emulsi untuk Perekat Pengerjaan Kayu. Jakarta: Badan Standarisasi Nasional. 
Ebnesajjad, S. (2011). Characteristics of Adhesive Materials. In S. Ebnesajjad (Ed.), Handbook of Adhesive and Surface Preparation - Technology, Applications and Manufacturing - Plastics Design (pp.137-183). William Andrew Applied Science Publishers. doi.org/10.1016/C2010-0-65918-9

Encyclopedia Britanica. (2020). Rug and carpet. Encyclopædia Britanica, Inc.

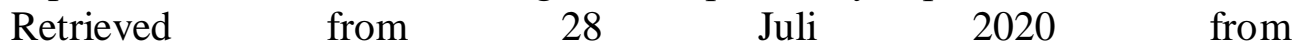
https://www.britannica.com/search?query=carpet.

Harsono, D. (2012). Pemanfaatan Batang Kelapa dan Kayu Karet sebgai Bahan Baku Glulam. Jurnal Riset Industri Hasil Hutan 4(2), 22-30.

Kaboorani, A and B. Riedl. (2015). Mechanical performance of Polyvinyl Acetate (PVA) Based Biocomposites. Woodhead Publishing, 347-364.

Martawijaya, A., I. Kartasujana, K. Kadir, SA Prawira. (2005). Indonesian Wood Atlas, Volume 1. Bogor: Departemen Penelitian dan Pengembangan Kehutanan.

Masripratin, N., E. Rachmawati, Y. Suryanti, H. Setyawan, M. Farid, N. Iskandar. (2017). Strategi Implementasi NDC (Nationally Determined Contribution).

Dirjen Pengendalian Perubahan Iklim. Jakarta: Kementerian Lingkungan Hidup dan Kehutanan.

Merle. (2017). Allergens: The Truth about Carpets vs. Hardwood. Retrieved from 29 Januari 2020 from http://www.hoosierhardwoodfloors.com/blog/2017/09/.

Merriam-Webster Dictionary. (2020). Definition of carpet. Merriam-Webster, Incorporated. Retrieved from 28 Juli 2020 from https://www.merriamwebster.com/dictionary/carpet.

Prabawa, S.B. (2017). The Experiment of Wood Carpet Making Through the Simple Process in order to Enhance the Communities' Welfare Opportunities, Proceedings of the Iufro - Inafor Joint International Conference 2017: "Promoting Sustainable Resources from Plantation for Economic Growth and Community Benefits". Bogor. Research, Development and Innovation Agency Ministry of Environment and Forestry - Republic of Indonesia. Halaman 183-190. 